\title{
Successful Outcome of Pregnancy with Huge Ovarian Cyst
}

\author{
Amruta Nandkishor Kharode ${ }^{1}$, Deepti Sandip Shrivastava² \\ 1,2 Department of Obstetrics and Gynaecology, Datta Meghe Medical College, Sawangi, Wardha, Maharashtra, India.
}

\section{INTRODUCTION}

Functional cysts of ovary and luteomas are the most common ovarian masses encountered during pregnancy. ${ }^{1}$ During customary medical follow-up most of them spontaneously disappears but some of them persist and further require surgical intervention which make the pregnancy a high risk one as well as challenging to manage for obstetrician and for the pregnant women. ${ }^{2}$

During pregnancy, benign epithelial neoplasms like mucinous cystadenoma of ovary can grow rapidly which can lead to torsion, virilization, inferior vena cava syndrome, preterm labour and fetal growth restriction. The incidence of surgery for ovarian tumours during pregnancy is 1:1312. The risks of fetal wastage, complications related to surgery, or a delay in diagnosis of a possible lethal disease or malignancy are the major concerns which affect the medical management of patient. Therefore, there is a dilemma in making decision to have surgery, although it is related to the nature of the emergency, such as twisting or rupture, tumor size, potential risk of complications, possibility of malignancy, gestational age at the time of intervention and maternal age..$^{1-3}$

Hereby we are reporting a case, having large ovarian cyst with pregnancy, managed conservatively, followed up and monitored critically till 38 weeks of gestation and removed at the time of caesarean section, successfully.

\section{PRESENTATION OF CASE}

A 27-year-old female, gravid two para one living one with previous caesarean section came in outpatient department for routine antenatal checkup. She had previous history of ovarian cystectomy too. Her routine antenatal profile was normal, and her obstetric ultrasonography showed left sided simple ovarian cyst $7 \mathrm{~cm}$ x $6 \mathrm{~cm}$ size along with single live intrauterine fetus of 20 wks. of gestational age. As she underwent 2 prior surgeries and she was asymptomatic, decision was taken not to intervene by doing cystectomy after counselling the patient and her relatives. She was advised routine checkup or follow up. Patient came for follow up at 28 weeks, ultrasonography was done to know the size of cyst and Doppler was done to look out torsion, there was increase in size of cyst to $12 \mathrm{~cm} \mathrm{x} 10 \mathrm{~cm}$ and as pregnancy had advanced, patient had breathlessness on and off. The cystic mass was managed conservatively with regular follow up of patient. Patient had a history of ovarian cyst after previous pregnancy which was managed by laparotomy and cystectomy, but histopathological report was not available.

Patient was taken for emergency caesarean section at 38 weeks as she came to casualty with complaint of premature rupture of membrane and large ovarian cyst (Figure 1) Intra-operatively, vertical midline incision was given and large ovarian cyst with multiple septations occupying whole abdomen was seen, it was tense large and measuring about in size $23 \mathrm{~cm}$ x $18 \mathrm{~cm} \times 12 \mathrm{~cm}$. Cyst was removed.
Corresponding Author: Dr. Amruta Tapre.

Meghe Heights,

Datta Meghe Medical College,

Sawangi, Wardha,

Maharashtra, India.

E-mail: tapreamruta@gmail.com

DOI: $10.14260 / j e m d s / 2020 / 791$

How to Cite This Article:

Kharode AN, Shrivastava DS. Successful outcome of pregnancy with huge ovarian cyst. J Evolution Med Dent Sci 2020;9(47): 3598-3600 DOI: $10.14260 /$ jemds/2020/791

Submission 19-07-2020,

Peer Review 08-10-2020,

Acceptance 15-10-2020,

Published 23-11-2020.

Copyright (C) 2020 Amruta Nandkishor Kharode et al. This is an open access article distributed under Creative Commons Attribution License [Attribution 4.0 International (CC BY 4.0)] 

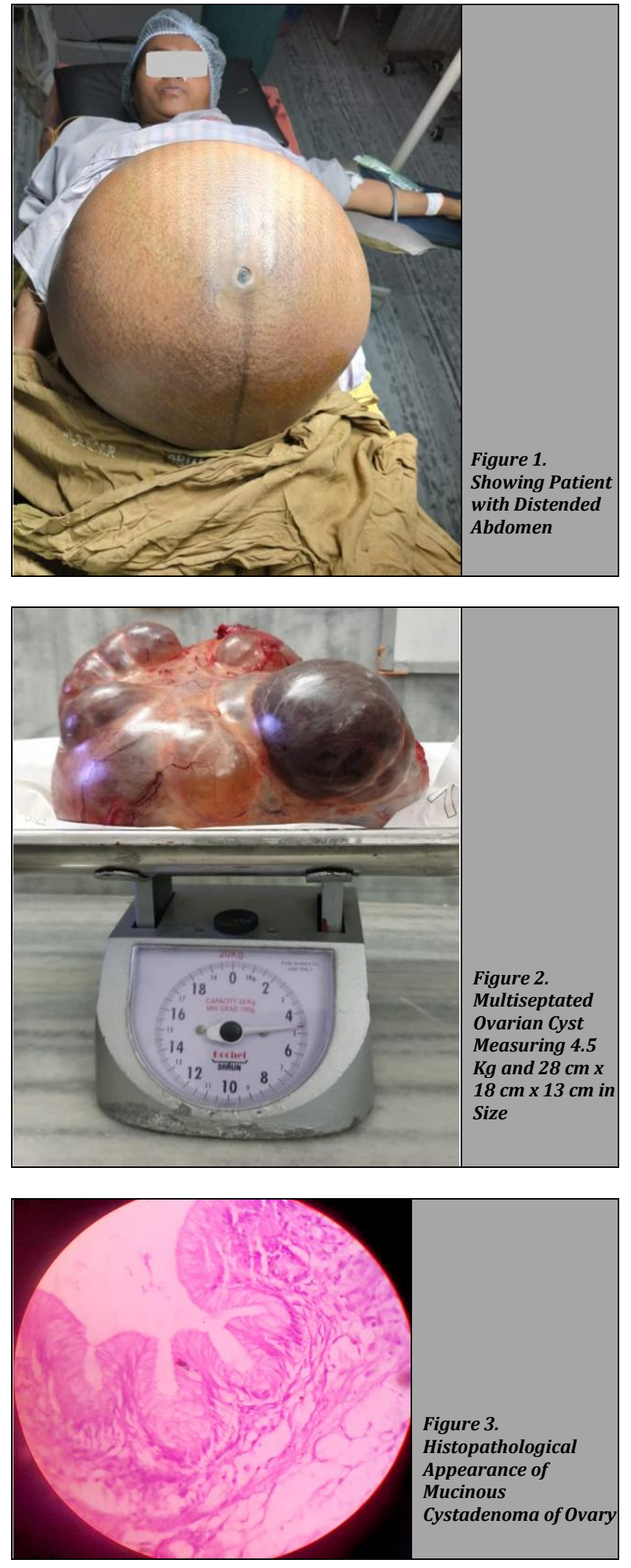

It was around $4.5 \mathrm{Kg}$ in weight (Figure 2). On gross examination it was smooth glistening cyst. A small nick given over cyst and 5 liters of straw coloured fluid suctioned out followed by delivery of a baby weighing $2.7 \mathrm{Kg}$, then we clamped, cut and ligated ovarian cyst and delivered it out of peritoneal cavity. Lax abdominal wall of 12 x $5 \mathrm{cms}$ was excised and skin tightening was done, abdomen was closed in layers. No haemodynamic and cardiac intraoperative modifications were observed. Ovarian cyst wall sent for histopathology and cystic fluid for cytopathology.

Histopathological examination was suggestive of papillary mucinous cystadenoma. (Figure 3). Postoperative period was uneventful, and patient was discharged with healthy baby on day 7 .

\section{DISCUSSION OF MANAGEMENT}

The frequency of coexistence of ovarian cancers with pregnancy is $1: 1000$. And of which only $1: 15000$ to $1: 32000$ turn out to be malignant. The most common ovarian masses are functional cyst of ovary. The other ovarian masses are benign cystic teratoma, paraovarian cyst, mucinous cystadenoma and endometriosis. Mucinous cystadenoma comprise 12 - $15 \%$ of all ovarian tumours. Around $75 \%$ of all mucinous tumours are benign while $10 \%$ are borderline, 15 $\%$ are invasive carcinomas. Most common serious complication of benign ovarian cyst is torsion, other are malignancy, infection, impaction of cyst in pelvis, malpresentation, obstructed labour. Management of ovarian masses during pregnancy is challenging, because the treatment decisions are associated with various complications, such as, unjustified termination of pregnancies, or inadequate treatment of a tumor resulting in compromised fetal health or cancer risk. Nowadays, ultrasound evaluation is widely used; which resulted in a higher rate of detection of adnexal masses during pregnancy and also of detection of asymptomatic and clinically not apparent lesions. ${ }^{1,4,5}$

However, important unanswered questions remain about how or when to treat pregnant women with asymptomatic and unsuspected cystic ovarian masses and who should be treated with adnexal mass surgery in pregnancy. For providing answers to these questions, some studies suggest that, after considering problems such as the risk of anesthesia, loss of the fetus, fear of malignant tumors, and anxiety about overtreatment of functional ovarian cysts (which often resolve spontaneously), preserving pregnancy and subsequent fertility; Any medical management strategy should be considered for the well-being of the mother or fetus which required regular monitoring with high-resolution ultrasound as well as paying attention to clinical signs and symptoms of ovarian cancer in pregnant women. ${ }^{1}$

Dipak Mandi et all in 2013 reported a case with successful outcome of pregnancy with huge ovarian cyst via vaginal delivery 4

Most of the ovarian tumours and functional cyst are originated from the corpus luteum especially in first trimesters and regress by 16 th week of gestation. Therefore, it is highly recommended to manage these masses conservatively, as most ovarian cancers in pregnant women disappear spontaneously during follow-up, only some of them persist and require further surgery. 2,6

Only 2 - $6 \%$ of adnexal masses detected during pregnancy are malignant. So it's important to differentiate between malignant ovarian tumors and other benign situations. Many scoring systems used to differentiate, it includes different malignancy characteristics, such as adnexal mass size (total volume $>50 \mathrm{~mL}$ ), septations (thick) and papillary projections (defined as solid projections into a cyst cavity from a cyst wall of $>3 \mathrm{~mm}$ in height), echogenicity (presence of a solid 
component), internal borders (wall thickness or irregularity), and resistance Doppler waveform with a pulsatility index $<1.0$ or a resistance index $<0.4-0.8 .^{7}$

The most serious and common complication of benign ovarian cysts in pregnancy is torsion. Most commonly encountered during first trimester. It can get rupture in the peritoneal cavity due to torsion, rupture of the ovarian cyst can occur during labour, delivery, immediate postpartum, so surgical delivery is always safe to remove the ovarian mass with good result. If these complications, like torsion and haemorrhage can occur should be managed immediately by laparotomy or laparoscopically. Doppler helps in knowing partial or complete torsion. Symptoms like abdominal pain nausea and vomiting should not be ignored in such conditions. Fetal complications of which obstetrician are worried are intrauterine growth retardation and preterm delivery. ${ }^{8}$

In our case we managed patient conservatively with critical monitoring along with the help of ultrasonography / Doppler, and we were able to know the fetal and ovarian status thoroughly. Patient carried till term, she had a previous history of caesarean section and there was a premature rupture of membrane; Therefore, she was taken for caesarian section and cystectomy done at 38th weeks.

\section{CONCLUSIONS}

Our case shows that though huge ovarian cyst may complicate the pregnancy, it can be managed conservatively with the proper monitoring. Proper strategy could be required for the treatment of patients having huge ovarian cysts during pregnancy like this, by keeping routine followed up clinically and ultrasonographically to prevent its adverse effects on pregnancy specially in patients, who had multiple pelvic surgeries, one additional surgery could be avoided if asymptomatic mass is noted and definitive surgery could be planned along with caesarean delivery and a thorough surgical evaluation of adnexa.

Financial or other competing interests: None.

Disclosure forms provided by the authors are available with the full text of this article at jemds.com.

\section{REFERENCES}

[1] Dahiya P, Latika. Ovarian mass in pregnancy: a case report. Int J Reprod Contracept Obstet Gynecol 2017;4(3):915-7.

[2] Koo FH, Wang KC, Chen CY, et al. An 11-year experience with ovarian surgery during pregnancy. J Chin Med Assoc 2013;76(8):452-7.

[3] Bolat F, Parlakgumus A, Canpolat T, et al. Benign mucinous cystadenoma with stromal luteinization responsible for maternal virilization and fetal intrauterine growth restriction. J Obstet Gynaecol Res 2011;37(7):893-6.

[4] Mandi D, Mondal RC, Bhar D, et al. Successful vaginal delivery despite a huge ovarian mucinous cystadenoma complicating pregnancy: a case report. Iran J Med Sci 2013;38(4):339-42.

[5] Goffinet F. Ovarian cysts and pregnancy. J Gynecol Obstet Biol Reprod (Paris) 2001;30(1 Suppl):S100-8.

[6] Whitecar P, Turner S, Higby MK. Adnexal masses in pregnancy: a review of 130 cases undergoing surgical management. Am J Obstet Gynecol 1999;181(1):19-24.

[7] Yacobozzi M, Nguyen D, Rakita D. Adnexal masses in pregnancy. Semin Ultrasound CT MR 2012;33(1):55-64.

[8] Chang SD, Yen CF, Lo LM, et al. Surgical intervention for maternal ovarian torsion in pregnancy. Taiwan J Obstet Gynecol 2011;50(4):458-62. 